\title{
Breve história do pós-humanismo: Elementos de genealogia e criticismo
}

\author{
Francisco Rüdiger ${ }^{1}$ \\ PUC-RS
}

\begin{abstract}
Resumo: Nosso objetivo é apontar as linhas gerais e grandes etapas de formação do movimento pós-humanista. Deseja-se salientar como se compõem nele, entre outros, os conceitos de trans e pós-humanismo. Tomando Nietzsche como ponto de partida da idéia, assinalam-se três momentos. O primeiro vai da época do filósofo até os anos 196o. O segundo corresponde à era de aparecimento do pensamento cibernético, dos 60 aos 198o. A última coincide com a organização dos grupos simpatizantes da idéia do pós-humano. Concluindo, o artigo lança alguns elementos para analisar o significado deste fenômeno de cibercultura sem mistificação, mas seriamente do ponto de vista histórico.
\end{abstract}

Palavras-chave: Pós-humanismo: história; cibercultura: pós-humanismo; história das idéias

\begin{abstract}
Our purpose is to signal the general lines and main formation phases of the posthumanist movement. We stress the composition between the concepts of trans and posthumanism that occurs in it. Considering Nietzsche as the idea's point of departure, three moments are indicated. The first one runs from the philosopher times to the 1960's. The second is correlated of the cybernetic thought emergency, from de sixties to the 1980's. The last one is marked by the organization of the posthuman idea by small groups of activists. Concluding, the article suggests some points to discuss the meaning of this cyberculture phenomenon without mystification but considering it seriously from a historical perspective.
\end{abstract}

Keywords: Posthumanism: history; cyberculture: posthuamismo; history of ideas

1 Professor da Faculdade de Comunicação da Pontifícia Universidade Católica do Rio Grande do Sul e Doutor em Ciências Sociais (USP). 
Resumè: Notre but ici c'est designer les lignes generaux et les grands étapes du movement post-humaniste. Nous considerons Nietzsche comme le iniciateur de l'idée et signalons trois moments dans leur development. Le premiére, vá de la époque du philosophe a le annes 196o. La second, coincide avec l'epanouissment de la pensée cybernétique. La derniérie, debut aprés les annés 1980 et c'est la étape de organization de petites groups de propagandistes. Pour finir, nous suggeróns quelques remarques sur le sens de cet phenomene de cyberculture, avec serieté du point de vie historique mais sans mystification.

Mots-clé: Post-humanisme: histoire; cyberculture: post-humanisme; histoire des idées.

Resumen: Nuestro objetivo es hacer um esbozo de las líneas principales e las grandes etapas de desarrollo del movimiento posthumanista. Nietzsche es visto como lo iniciador de la idea e tres momentos mayores son descriptos. El primer, se extiende de la época del pensador a los 1960. Lo segundo, coincide con lo desarrollo de pensamiento cibernético. Lo ultimo empieza después de los 1980 e se caracteriza por la organización de pequeños agrupamientos de activistas. En el final hacemos algunas sugerencias sobre la significación de este fenómeno de cibercultura desde un punto de vista histórico.

Palabras clave: Posthumanismo: historia; cybercultura: posthumanismo; historia de las ideas.

Nietzsche aparentemente foi o primeiro a falar com sentido enfático na necessidade de, menos tentar se aperfeiçoar, do que se superar a espécie humana: é esse o sentido mais evidente de suas menções ao supra-humano. Depois dele, foram poucos, porém, os que falaram em termos positivos sobre essa figura, se deixarmos de lado as pretensões a seu respeito surgidas durante a era nacional-socialista, na Alemanha.

Hoje, verifica-se que os propagandistas dessa figura não são muito mais, mas dela se originaram sucedâneos, que, embora causem algum espanto, se revestem de menos antipatia e não pesam apenas na formação do cenário intelectual: eles também influem nos rumos da tecnociência contemporânea. Entre as vanguardas, assume-se, cada vez mais, que o impulso no sentido de transformamos tecnicamente a nós próprios e a natureza é algo que nos é central. "Nietzsche o reconheceu através de sua visão universalista sobre a vontade de poder", como disserta o guru do finado grupo extropriano, Max More (cf. 1994). 
Noutros termos, registra-se assim o surgimento de um movimento póshumanista, cuja força e interesse provêm do fato de estar parcialmente encaixado nas engrenagens empresariais e tecnológicas que estruturam nossa civilização.

"Nos próximos 50 anos, a inteligência artificial, a nanotecnologia, a engenharia genética e outras tecnologias permitirão aos seres humanos transcender as limitações do corpo. O ciclo da vida ultrapassará um século. Nossos sentidos e cognição serão ampliados. Ganharemos maior controle sobre nossas emoções e memória. Nossos corpos e cerébro serão envolvidos e se fundirão com o poderio computacional. Usaremos essas tecnologias para redesenhar a nós e nossos filhos em diversas formas de póshumanidade" (More, 1994, Internet).

Conforme postulam os próprios defensores do movimento, a "pessoa" possuidora de capacidades físicas e intelectuais sem precedentes, a entidade possuidora dos princípios de sua autoformação e um caráter transcendente, porque potencialmente imortal, é pós-humana, seja ciborgue ou máquina de inteligência artificial. Quem atinge esse ponto não mais pode ser chamado de humano, e é para se chegar até ele e converter-se em pós-humanos que muitos crentes na tecnologia vêm se organizando desde o final do século XX.

Concordemos ou não com suas idéias, o relevante no caso é que existe agora uma vanguarda disposta a fazer da natureza humana objeto de experimentação, um coletivo que começa a se entender menos como sujeito do que como projétil lançado contra o humano pela ciência e tecnologia maquinísticas. Segundo alguns de seus observadores, o movimento pós-humanista que assim vai surgindo não seria nada mais "do que confusão intelectual, estupidez e desejo horrendo, elaborado em uma ideologia consciente, aplicada ao conjunto das tecnologias potencialmente definidoras do século 21" (Jahn, 2001). Para outros, o fenômeno se reduziria "a uma fantasia de caráter semi-escapista, semi-religioso, que reflete uma fé estranhamente datada, inspirada nos desenhos da família Jetson, no progresso científico e em sua capacidade de resolver todos os males que nos assaltam” (Horgan, 2004).

Julgamos que se pode propor uma leitura menos estreita do que está em jogo nesse processo. O movimento pós-humanista não deveria ser julgado pelo seu valor de face, nem ser reduzido à fantasia desejante. O caráter delirante de suas fantasias não deve nos cegar para o fato de que elas são, muitas vezes, propostas por pessoas bem encaixadas no sistema de poder vigente e por grupos de ativistas com 
acesso a vários meios de comunicação. Além disso, as tecnologias criadoras de realidade virtual, a engenharia genética, a medicina restauradora, as operações de mudança de sexo, as próteses de todos os tipos, para não falar da exploração de outros mundos, insinuam que já está em curso um processo bastante perturbador e profundo de modificação da condição humana.

Nosso objetivo, neste trabalho, consiste, primeiramente, apontar os elementos formadores desse movimento, salientando como se compõem nele, entre outros, os conceitos de trans e pós-humanismo. Depois, propomos um referencial para discutir seu significado sem mistificação, mas considerando seriamente os pontos críticos e novidades embutidos nesse fenômeno de cibercultura, do ponto de vista da reflexão histórica e filosófica.

Embora sejam inexpressivos socialmente e talvez não tenham longa vida pela frente, devido ao seu cunho ainda humano, demasiadamente humano, tanto quanto pela sua irrelevância diante dos problemas sociais de nossa época, o movimento pós-humanista importa para quem se interessa pelo nosso futuro. Em função não apenas de seu extremismo e caráter virtualmente delirante, mas também de suas contradições internas e oposições externas, o fenômeno indica a natureza dos problemas e as perspectivas em torno das quais ocorrerão conflitos profundos e radicais na era da biopolítica, como chamou Foucault.

\section{Primeiras notícias}

Durante o século XX, chegou-se várias vezes a temer pelo futuro do homem, por causa das guerras mundiais, da contaminação nuclear ou da poluição ambiental. Nesse período, parece que houve uma forte preocupação com a sorte do homem. Atualmente, o panorama está em vias de mutação, existem cada vez mais publicistas proclamando o virtual fim de nossa era. Em diversos lugares da terra, pesquisas de concepção futurista começam a projetar o eventual abandono da condição humana nos próximos séculos. Os partidários se recusam a aceitar as limitações tradicionais que nos definiam, tais como a doença, o envelhecimento e a morte, rejeitando os paradigmas convencionais que tentam tornar nosso mundo confortável a expensas da nossa completa realização. 
Os movimentos eugenistas do passado pretendiam fazer a raça humana mais pura, mas ainda humana. Os partidários do pós-humanismo crêem que chegou a hora de se ir além, de se buscar um estágio mais avançado, em que não mais seríamos humanos. A pretensão de torna-la mais forte, mas bela e mais inteligente se baseava na idéia de natureza humana. O projeto de fazê-lo vencer a morte, supõe que essa pode ser ultrapassada. Antes, o objetivo mais comum era, ainda que a longo prazo, beneficiar toda a humanidade. A fantasia que agora anima os esforços de parte de nossa vanguarda é chegar à pós-humanidade.

Paula Sibilia nota que "enquanto as próteses clássicas se inspiravam na metáfora do robô, a tecnociência [...] de vocação ontológica abandona o modelo mecânico para assumir de vez a analogia digital e submeter o organismo ao upgrade informático" (2002: 137). Na verdade, cremos que tende a haver agora uma fusão ou movimento de complementação entre esses dois extremos. Neste novo contexto, a essência do ser se torna a informação, e seu sentido é cada vez menos humano, vinculando-se em última instância à máquina. O humano é visto como tendo sua essência na mente, e essa como passível de ser entendida como um sistema de informações encarnado numa virtual máquina.

Aparentemente, as primeiras proclamações reflexivas sobre uma nova época, pós-humanista, remontam há cerca de trinta anos atrás. As filosofias anti-humanistas apresentavam, então, argumentos com os quais pretendiam comemorar vitória. "Quinhentos anos de humanismo podem estar assistindo agora ao seu fim, quando assistimos sua transformação em algo que podemos desesperadamente chamar de pós-humanismo" (Hassan, 1977: 212).

$\mathrm{Na}$ verdade, o movimento pós-humanista, entendido em sentido amplo, possui várias frentes de manifestação. Sterlac é apenas um dos artistas mais conhecidos a se manifestarem em favor desse projeto, que visa reprojetar o corpo biológico para o novo ambiente maquinístico ou, pelo menos, meditar sobre nosso ingresso no ambiente maquinístico. A literatura, a música e o cinema e outras artes estão já estão bem marcados por ele, como nos dá sinal o trabalho de artistas como Natascha Vita-More, Bruce Sterling, Luis Royo ou Charles Platt (cf. Santaella, 2003). 
A conexão entre criação artística e progresso técnico não ocorre por acaso, porque, como se tem notado, a tecnociência se projeta com a exigência feita no sentido de se expressar através de ficções. O fenômeno é inseparável do aparecimento de textos e imagens capazes de o ligar aos seres humanos de maneira não esotérica ou especializada. "Para a técnica, a ficção não é simplesmente uma aliada ocasional: é uma aliada necessária; ao abrir os possíveis, ela prepara os espíritos para acolher a inovação que já esboçou na narração e que ela situou como ação em situações verossímeis" (Sfez, 2002: 235).

William Gibson cunhou o termo em seus contos de ficção-científica do início dos anos 1980 e, assim, transmitiu-nos a idéia de ciberespaço. Arthur Clarke escreveu sobre a descarga da mente em computadores no livro The city and the stars (1956). Em Marooned in Realtime (1986), Vernor Vinge elaborou plasticamente a expressou singularidade tecnológica, que hoje motiva os interessados no desenvolvimento de uma inteligência supra-humana. Reencontramos esse fenômeno ao tratarmos do movimento pós-humanismo. Em 1952, Van Vogt sugeriu o termo pós-humano, para designar uma outra raça criada pelo ser humano em seu conto Slan. Bruce Sterling empregou a expressão em Schizmatrix (1985), relançando-a em novo contexto de desenvolvimento tecnológico. Em bases ensaísticas, o sentido que o termo passou a ter em seguida parece, porém, ter sido explorado pela primeira vez por James Bernal, em 1929 (The World, the Flesh and the Devil: An Enquiry into the Future of the Three Enemies of the Rational Soul)

Julian Huxley usara a expressão trans-humanismo para denominar da crença de que a espécie humana pode transcender às suas circunstâncias de forma global e permanente. Em 1927, o sentido do termo não portava, porém, mais do que um significado moral. Huxley entendia que, através da técnica, "a espécie entrará no limiar de uma forma de existência, tão diferente da nossa quanto esta o é da do Homem de Pequim". Porém, estava bem claro para ele que, nesse processo de transcendência, "o homem continuaria sendo homem": a diferença seria "a percepção de novas possibilidades da e para a natureza humana" (Internet).

Pouco tempo antes, James Joyce sugerira em carta a Harriet Weaver (8/11/1922) que somos um intervalo entre duas eras, a pré e pós-humana, dando senha para uma especulação que, todavia, acabou sendo explorada no último sentido 
por J. D. Bernal. Quem hoje lê, por exemplo, os textos futuristas de Earl Cox ou Ray Kurzweill se surpreenderá com o seu caráter de mera reatualização de uma fantasia prospectiva que se encontra no mencionado The World, the Flesh \& the Devil.

Apesar de não ter usado o termo em foco, o físico e escritor inglês especula neste ensaio sobre "o curso a ser seguido por uma ser humano transformável", observando que, no seu término, esse ser nos pareceria, por tudo, "uma criatura estranha, monstruosa e inumana". Segundo ele, a humanidade faz frente historicamente a três inimigos principais: a realidade, o mal e a morte. A mecanização do homem provavelmente se revelará uma solução para todos esses problemas. O tempo mostrará que ela pode ser vantajosa, em comparação com as nossas condições biológicas naturais ou nossas utopias políticas.

"O homem normal é um ponto final da evolução; o homem mecânico, à primeira vista, uma ruptura na evolução orgânica; realmente é um salto no sentido de uma evolução adicional, capaz de instalar uma [nova e] verdadeira tradição" (Bernal [1929] 1969, Internet).

Concluindo em termos que, em última instância, serão mais tarde os mesmos, embora com acento místico, os de Teilhard de Chardin (1940) e sem tanto, mas conotações igualmente delirantes, os de Gregory Stock (1993), Bernal afirma que, via maquinização, a natureza seria superada por uma nova forma de vida, mais plástica, mais forte e controlável. Seria um processo que, passo a passo, faria desaparecer as formas humanas que conhecemos até o momento. "Eventualmente elas seriam preservadas relíquias curiosas, enquanto a nova forma de vida, conservando o espírito da antiga, mas não sua substância, as substitui e continua seu desenvolvimento".

\section{A segunda onda}

Norbert Wiener e os ciberneticistas não fizeram senão transformar essa fantasia em princípio de construção tecnológica. Durante as Conferencias Macy sobre Cibernética (1943-1954), eles se dividiram entre uma visão do homem como mecanismo homeostático auto-regulado e outra, na qual é visto como ponto de passagem de um circuito de informações (Hayles, 1999: 50-83). Depois, porém, acabou se firmando a concepção segundo a qual, conforme o pensamento cibernético, 
os seres humanos não são tanto carne e osso, quanto padrões ordenados de informação (Thomas, 1995).

Desse credo ou entendimento originador do movimento pós-humanista provém por sua vez o conceito já mencionado de singularidade, de uma situação totalmente nova e eventualmente catastrófica para a humanidade que estaria em vias de ocorrer devido ao progresso científico-maquinístico. John von Neumann teria sido o pai dessa expressão, ao repetir para Stam Ula, nos 1950, que o progresso tecnológico provocaria uma mudança radical no ser humano. Segundo ele, relata esse autor, chegaremos num estágio em que ocorrerá "alguma singularidade essencial à história da raça humana e para além da qual os problemas humanos, tais como os conhecemos, não poderão prosseguir sendo tais” (1958)

Cerca de vinte anos depois, Robert Ettinger conferiria ao termo transhumano um significado vinculado a essa idéia de uma (nova) singularidade. Fundando-o numa condição instaurada pela tecnologia, ele o usa no sentido de vetor para a superação do homem. Autor da obra curiosamente intitulada Do Homem ao Super-homem (1972), o empresário e publicista criou a doutrina que levaria à criação de empresas para a preservação de cadáveres nos anos 1960.

Também oriunda dos textos de Wiener é a idéia de organismo cibernético, ciborgue, surgida nos anos 1960. Manfred Clynes e Nathan Kline cunharam a expressão no contexto da pesquisa aeroespacial, servindo para designar os sistemas ou entidades auto-reguladas formadas com o acoplamento de homem e máquina. Em seguida, D. S. Hallacy começou a propagandear a idéia em sua obra Ciborgue: evolução para o super-homem (1965). Nos 1970, verificou-se a abertura de espaço para seu uso na ficção científica (cinema, televisão, literatura, brinquedos e HQ). Enfim, Donna Haraway e Antonio Caronia começaram a elaborar uma reflexão crítica sobre a figura em seus Manifesto ciborgue e O ciborgue (ambos de 1985), dando, de certo modo, desenvolvimento às idéias precursoras lançadas por Henri Lefebvre (Rumo ao cibernantropo: contra os tecnocratas, 1967).

Como Timothy Leary e outros membros do grupo futurista da Sociedade L5 a partir de meados dos anos 1970, F. M. Esfandiary (“FM-2030"), professor e diplomata de origem iraniana, falecido em 2000, contudo já se apresentava nos 
campi universitários norte-americanos como trans-humanista por essa época. Despontando na cena política e em ambientes corporativos como tecnoguru, era com esse termo, trans-humanista, que ele chamava aos seres humanos em fase de transição. Para ele, é tal "aquele que em virtude do emprego de tecnologias, dos valores culturais e do estilo de vida constitui um elo evolutivo com a futura era póshumana" (1978: 15).

Defensor de uma tecnocracia benevolente e animada por metas interiores, o publicista defendia que os sujeitos desse processo são os cientistas, inventores, técnicos e artistas de vanguarda: são eles os trans-humanistas. Lideranças dos movimentos futuristas, esses grupos são os revolucionários de nosso tempo, os estrategistas da conexão entre tecnocracia e ficção, conforme a qual se poderá alterar a condição humana de forma fundamental.

Durante os 1980, os apoiadores desse tipo de idéias começaram a formar grupos para discutir suas teses e propagar suas convicções a respeito, sobretudo tópicos como longevidade existencial, crionização, colonização espacial, robótica, informatização da sociedade. Porém, permaneceram isolados uns dos outros e, embora tivessem valores e vistas comuns, eles não lograram chegar a uma concepção unificada do que seria sua visão de mundo e como ela poderia ser agenciada praticamente.

Conforme vimos foi nessa época também que, contudo, começou a ser falar de um modo mais próprio de pós-humano e, além disso, surgiram não apenas suas exposições seminais, mas as principais obras dos gurus contemporâneos dos póshumanistas, tais como Hans Morave. Eric Drexler e Marvin Minsky (Regis 1990). Durante essa época, em especial, surgiu "a idéia de se descarregar a mente numa máquina, de transferir a mente humana para uma rede neuronal artificial, através da eventual substituição das células cerebrais por circuitos eletrônicos e conexões funcionais semelhantes". Seria esse o modo de "projetar-nos num novo tipo de existência, onde nossa humanidade não seria apenas preservada mas ampliada de formas que dificilmente podemos imaginar" (Daniel Crevier apud Noble, 1999: 161).

Para os porta-vozes da idéia, a pessoa, com efeito, não passa de um processador de informações, cujo centro de dados é o cérebro. $\mathrm{O}$ pensamento 
cibernético triunfa. O corpo se torna algo com pouca ou nenhuma relevância. Chegará um dia em enviaremos todas as suas informações para uma base artificial, arquivando-o de modo a ser usado nos mais diversos equipamentos. Você viverá, portanto, enquanto ele puder ser copiado e posto em operação em algum maquinismo.

Segundo muitos trans-humanistas, as nanotecnologias são a chave de nosso futuro pós-humano. [...] Baseado nisso, poderíamos carregar nossas mentes em computadores e fazer cópias de cada um de nossos desejos, de nossas últimas esperanças, de nossos traços de personalidade e de cada uma de nossas lembranças. Enfim, poderíamos desenhar corpos novos e melhores, ou simplesmente viver como padrões de informação existentes nas redes de computadores, como se fossemos fantasmas de um vasto maquinismo (Elliott, 2003, Internet).

Conforme os estudiosos do fenômeno tem observado, o pós-humano significa contudo muito mais do que dispor de próteses acopladas ao corpo: significa nos ver como máquinas processadoras de informação, significa nossa subjugação ao pensamento tecnológico da atualidade, o pensamento cibernético.

\section{Panorama contemporâneo}

Em 1988, Max More e Tom Bell começaram com algumas dezenas de exemplares a publicação da Extroprian Magazine, embrião do instituto do mesmo nome, fundado em 1991. A proposta dos visionários era desenvolver estudos e promover ações contra a entropia que, crêem, ameaça a humanidade. O passo seguinte foi criar uma lista de discussão via internet, que se tornou cult e começou a projetar o grupo entre os partidários da tecnocracia vanguardista. Quando promoveram o seminário Extro I (Sunnyvale, CA, 1994), o número de simpatizantes já era uns poucos milhares, mas entre eles havia gente de prestígio, como os já mencionados Hans Moravec, Marvin Minsky e Eric Drexler.

O Instituto Extropriano apresentou-se ao público como um laboratório de idéias a respeito das mudanças produzidas pelo desenvolvimento tecnológico. Durante seu breve período de vida, propôs-se, em essências, a reunir pessoas intelectualmente privilegiadas para pensar o futuro humano em sentido radical.O fundamento em transformação desse trabalho seria uma filosofia trans-humanista, a filosofia da Extropria. 
Originalmente, os extroprianos possuíam claros compromissos com o pensamento libertário capitalista, substituído nos últimos anos pela idéia popperiana de sociedade aberta. Para eles, o controle politico centralizado deve ceder lugar à iniciativa individual responsável, ao chamado princípio proacionário. No final de 2005 o Instituto, todavia, encerrou suas atividades, considerando sua missão "essencialmente realizada", convertendo-se, com outra marca, numa entidade de assessoria sobre o impacto do desenvolvimento de novas tecnologias.

Em comparação a ele, os transtopianos formam um agrupamento insignificante de idéias extremistas e perigosas, que nasceu por volta de 1997. Embora suas conexões com a extrema direita internacional sejam claras, sabemos pouco sobre quem são e quais são seus líderes. Suas origens estão ligadas ao Projeto Transtropriano, que pretendia criar um estado-nação numa flotilha ou ilha abandonada. Pretendia-se que, num ou noutro espaço, pudessem os interessados praticar o aborto, a eutanásia, a clonagem, a criogenia, cirurgias radicais, experimentos com drogas, procedimentos neo-eugenistas e outras práticas trangressivas, sem qualquer espécie de impedimento institucional.

Os extroprianos defendiam o livre uso da razão para desenvolver a pesquisa científica e o desenvolvimento de novas tecnologias. Os transproprianos baseiam-se no mesmo princípio para defender a pura e simples imortalidade. Ambos reconhecem uma dívida filosófica para com Nietzsche. Os transproprianos, contudo, são mais radicais, presumindo-se liberados mentalmente das cadeias da moralidade tradicional. O desejo que os move é de transcender as limitações da carne e, por essa via, ingressar numa existência pós-biológica. A motivação em um e outro grupo, contudo, é a mesma: o auto-interesse esclarecido, como eles dizem, tomando apoio nas idéias libertárias da anarco-capitalista Ayn Rand.

"O transproprianismo é uma filosofia da liberdade: liberdade diante dos falsos deuses, liberdade em relação a leis tirânicas, liberdade em relação à ignorância; liberdade em relação a dor e à própria morte. [...] Os trasnproprianos desejam levar o processo de capacitação individual à sua conclusão lógica e se assegurar de uma existência ilimitada dentro de condições ótimas [...] Os transproprianos são extremistas apenas no contexto de um mundo dominando pelo conservadorismo religioso, pelo socialismo igualitário e outras ideologias ridiculamente arcaicas" (cf. www.transtopia.org). 
Depois de 2001, mais ou menos, os propagandistas da causa começaram a defender uma versão apocalíptica da tese sobre o evento singular ou singularidade, passando a pregar a formação de pequenos grupos para enfrentar o período de apocalipse, com vistas ao seu ingresso no mundo pós-humano. O projeto no sentido de criar uma comunidade alternativa foi posto de lado. "Destarte, uma das maiores metas de nosso projeto será formar um grupo de ajuda mútua, com o propósito de fornecer a seus integrantes uma boa posição preparatória para a Singularidade”.

Nesse sentido, os transproprianos constituem apenas um entre os vários grupúsculos para os quais estamos em vias de passar por uma mutação radical e violenta, que deixará para trás a humanidade conforme nos a conhecemos. Para esses agrupamentos futuristas, eles mesmos são apenas o estágio final de uma evolução que culminará com o advento da era pós-humana. A espécie humana será extinta com sua chegada, coincidem esses novos apocalípticos, partidários de uma idéia lançada pelo matemático e escritor de ficção-científica Vernor Vinge, em 1993.

No século 21, haverá a ascensão de uma espécie alienígena em um mundo no qual as atuais convenções não mais serão aplicáveis. O cenário é incerto, poderá ser o céu, mas também um inferno. Apenas é certo que a vida, tal como a conhecemos, desaparecerá. Diante dessas idéias, a originalidade dos transproprianos e outros grupos pós-humanistas reside no fato de significarem como moralmente positiva a possibilidade apocalíptica da singularidade, demonstrando que tecnófilos e tecnófobos compartilham da mesma crença de fundo no poder da tecnologia.

Contra essas tendências de extrema-direita e as fantasias de uma espiritualidade fundada em todo o tipo de ficção científica de grupos como os raelianos, mas não menor pensamento tecnológico e utopia futurista posiciona-se o agrupamento pós-humanista mais consistente e representativo surgido até o momento: A World Transhumanistic Association.

Fundada em 1998 por Nick Bostrom e David Pearce, a associação congrega atualmente cerca de 15 entidades, possuindo quase quatro mil sócios de uns cem países (2006), e se propõe a servir de plataforma organizacional para os grupos interessados em promover o pós-humanismo. Existem seções em doze países e seus quadros incluem pesquisadores de várias empresas e sociedades científicas, tais como 
a Alcor life, O Foresight Institute, o Singularity, The Society of Neuronal Prostethic, etc.

A WTA rejeita coloração política: em seus quadros, encontramos um espectro que vai da direita à esquerda, do conservadorismo ao esquerdismo. $\mathrm{O}$ objetivo é livrar o trans-humanismo da inconsistência cultural que, segundo seus críticos, possuiria, promovendo sua respeitabilidade acadêmica, moral e intelectual. Advoga-se o uso ético da tecnologia para expandir e eventualmente ultrapassar positivamente as capacidades humanas e opera regularmente através de publicações via Internet, onde também existem fóruns de discussão permanentes.

A WTA pretende fazer proselitismo e poder contar com pessoas capazes de desenvolver atividades publicísticas nos âmbitos escolar, científico, propagandístico, jornalístico e governamental. O Journal of Transhumanism (1998) foi sua primeira publicação acadêmica, atualmente editada online com o título de Journal of Evolution and Technology.

Resumindo, afirmaríamos, à luz do visto, que o pós-humanismo é um movimento desarticulado de agrupamentos, concepções, filosofias e estilos de vida que ambiciona controlar o mundo e transcender a condição humana, conforme anunciado por Bernal.

\section{Anúncios de uma aventura perigosa?}

Rémi Sussan tem razão, cremos, em afirmar que esses movimentos, em geral, tendem a ter vida curta, provavelmente não conseguirão se converter em pensamento influente junto às massas, porque lhes falta "uma verdadeira compreensão dos desejos humanos no que eles possuem de menos racional, de mais frouxo, de mais poético, das tantas pulsões que eram satisfeitas pela contra-cultura [da qual provieram], mesmo que isso ocorresse às custas do rigor científico" (2005: 178).

Porém, também convém ver o problema no sentido oposto e perguntar se esses movimentos, ao contrário, não são sintomas de uma metamorfose no pensamento que se expressa em outras vias e que se propaga de forma cada vez mais ampla por nossa atualidade. Vendo bem, apostamos, os movimentos pós-humanistas 
precisam ser conhecidos porque reverberam intelectualmente uma sensibilidade cultural e um projeto tecnológico que podem a abalar nosso mundo histórico muito rapidamente. Figuras como Kevin Warwick, Wendy Carlos, Stephen Hawkins e outros são prova de que os ciborgues não são apenas personagens ficcionais, mas entidades que poderão se tornar cotidianas.

Durante séculos, o homem teve de se submeter aos mais variados tipos de rituais, que inscreviam em seu corpo as marcas e obrigações prescritas pela ordem coletiva. Agora parece estar se esboçando em nosso horizonte o aparecimento de um indivíduo experimental, conforme o qual nossa identidade cultural e biológica se predispõe à intervenção tecnológica e maquinística. A condução da vida se pauta por princípios tecnológicos, depois de ter se guiado por normas religiosas, políticas e morais. Somos cada vez mais inclinados a fazer transplante de órgãos, cirurgias plásticas, fortalecer a saúde, prevenir doenças, consumir drogas, etc. que apontam para um devir ciborgue.

"Neste começo de século 21, as esperanças, temores, decisões e rotinas de vida modeladas em termos dos riscos e possibilidades existentes na nossa existência corporal e biológica suplanta quase todas as outras como princípios organizadores da um vida baseada na prudência, responsabilidade e escolha" (Rose, 2006: 18)

Segundo Nancy Hayles, o pós-humano significa a superação do sujeito liberal humanista, responsável por tantos de nossos pesadelos históricos. Nesse sentido, apenas eventualmente significa um ciborgue ou pior, uma entidade maquinística. Quer haja ou não alterações no corpo, o processo do pós-humano todavia já está aberto, porque é um processo performativo, ainda que não universal. "Os novos modelos de subjetividade que emergem de campos como a ciência cognitiva e a vida artificial implicam que mesmo um homo sapiens biologicamente inalterado já conta como pós-humano" (Hayles, 1999: 4).

Destarte, o problema não consistiria mais em saber se seremos póshumanos, porque essa via já se pôs em marcha, mas sim o tipo de pós-humanidade que possuiremos:

"Subjacente a nossas obsessões está a questão oportuna: quando o humano encontra o pós-humano, será um encontro para pior ou para melhor? O pós-humano preservará o que continuamos a valorizar no sujeito liberal? Ou esse será aniquilado quando houver 
a transformação? Num futuro pós-humano ainda haverá agencia individual e vontade livre? Serenos capazes de nos reconhecemos após a mudança? Ainda haverá eu para reconhecer e ser reconhecido?“ (p. 281)

O progresso técnico é um dos eixos através dos quais aprendemos a buscar alívio para nossos sofrimentos e condições mais favoráveis de sobrevivência, mas ele também pode se tornar, como é fato constado na história, uma das formas de obtermos poderio político sobre os outros, impormos privilégios econômicos e praticarmos todo o tipo de violência contra a natureza e nossa própria espécie.

"A expectativa de uma salvação última por meio da tecnologia, independente do seu custo imediato em termos sociais e humanos, tornou-se com o tempo uma ortodoxia silenciosa, reforçada por um entusiasmo induzido mercadologicamente pela novidade e sancionado por um anseio milenarista que pede novos começos" (Noble, 1999: 207)

Atualmente, a pesquisa científica depende menos da procura de conhecimento do que da geração de valor através de criação de produtos, a exploração econômica da vida mesma ainda é mais relevante do que a elaboração do saber a seu respeito e a pesquisa de uma forma de vida menos causadora de opressão, sofrimento e desigualdades.

Os movimentos pós-humanistas e seu questionamento são uma projeção ao mesmo tempo fantasiosa e intelectualizada da emergência de um novo cenário, em que isso, em parte de forma alienada, em parte de forma reflexiva, pode vir a ter uma mudança de direção.

O aparecimento de lutas sobre a experimentação científica, sobre o sentido da pesquisa biogenética, pelos recursos públicos investidos em tecnologia, pelo reconhecimento de novos direitos, por mudanças de sexo, pela reprodução artificial, sobre a exploração do próprio corpo, o consumo de drogas, etc. é sinal de que a cibercultura provavelmente será cenário de uma redefinição do que seremos e do implica o poder na era da técnica maquinística.

Para concluir, acontecimentos como esses projetam um novo cenário de lutas, cujo foco, mais do que a vida, é algo em que está em jogo a própria definição do que é ser humano (cf. Rose, 2006). 


\section{Referências}

Bernal, J. D. The world, the flesh \& the devil. Bloomington: Indiana University Press, 1969 (Internet).

Bostrom, Nick. History of Transhumanist Thought Journal of Evolution and Technology - Vol. 14 - April 2005

Elliott, Carl. Transhumaniusm: Humanity 2.0 Wilson Quarterly, Autumn 2003 (Internet).

FM-2030. Are you a transhuman? Nova York: Warner Books, 1989.

Fukuyama, Francis. Nosso futuro pós-humano. Rio de Janeiro: Difel, 2002.

Gray, Chris (org.) The cyborg handbook. Londres: Routledege, 1995.

Haraway, Donna. O manifesto cyborg. In David Bell \& Barbara Kennedy (orgs.): The cybercultures reader. Londres: Routledge, 2000.

Hayles, Katherine. How we became posthuman. Chicago: University of Chicago Press, 1999.

Horgan, John. Brain chips and other dreams of the cyber-evangelists. In Chronicle of higher education no. 3 (Internet, 2005)

Hughes, James. Citizen cyborg. Bolder: Westview Press, 2004.

Jahn, Karl. In Defense of Humanity: Against Transhumanis (Internet, 1999)

Kurzweil, Ray. The age of spiritual machines. Nova York: Penguin, 1999.

Leary, Thimothy. Info-psychology. Nova York: New Falcon, 1987.

Moravec, Hans. Robot. Nova York: Oxford University Press, 1999.

More, Max. On Becoming Posthuman. Extropian Journal, 1994 (Internet).

Noble, David. The religion of technology. Nova York: Penguin, 1998.

Overhage, Paul. A caminho da pós-humanidade. Petrópolis: Vozes, 1970.

Regis, Ed. Great Mambo Chicken and the Transhuman Condition. Woburn(MA): Perseus, 1990.

Rose, Nikolas. The politics of life itself. Oxford: Blackwell, 2006.

Santaella, Lucia. Culturas e artes do pós-humano. São Paulo: Paulus, 2003.

Santos, L. G. Politizar as novas tecnologias. Rio de Janeiro: 34, 2003.

Sfez, Lucien. Técnica e ideologia. Lisboa: Instituo Piaget, 2002.

Sibilia, Paula. O homem pós-orgânico. Rio de Janeiro: Relume-Dumará, 2001.

Stock, Gregory. Metaman. Nova York: Simon \& Schuster, 1993.

Sussan, Rémi. Les utopias posthumaines. Paris: Omniscience, 2005.

Vinge, Vernon. On the Singularity. Trabalho apresentado no VISION-21 (NASA Lewis Research Center and the Ohio Aerospace Institute, March 30-31, 1993 Internet). 


\section{Internet}

www.transhumanism.org.

www.extropy.com

www.transtopia.org.

www.cosmotheism.net

www.minduploading.org.

www.kurzeillAl.net

www.aleph.se/Trans

www.foresight.org.

www.betterhumans.com

www.jetpress.org

www.vastmind.com 